Supplement of

\title{
Pyruvic acid in the boreal forest: first measurements and impact on 5 radical chemistry
}

Philipp G. Eger et al.

Correspondence to: John N. Crowley (john.crowley@mpic.de)

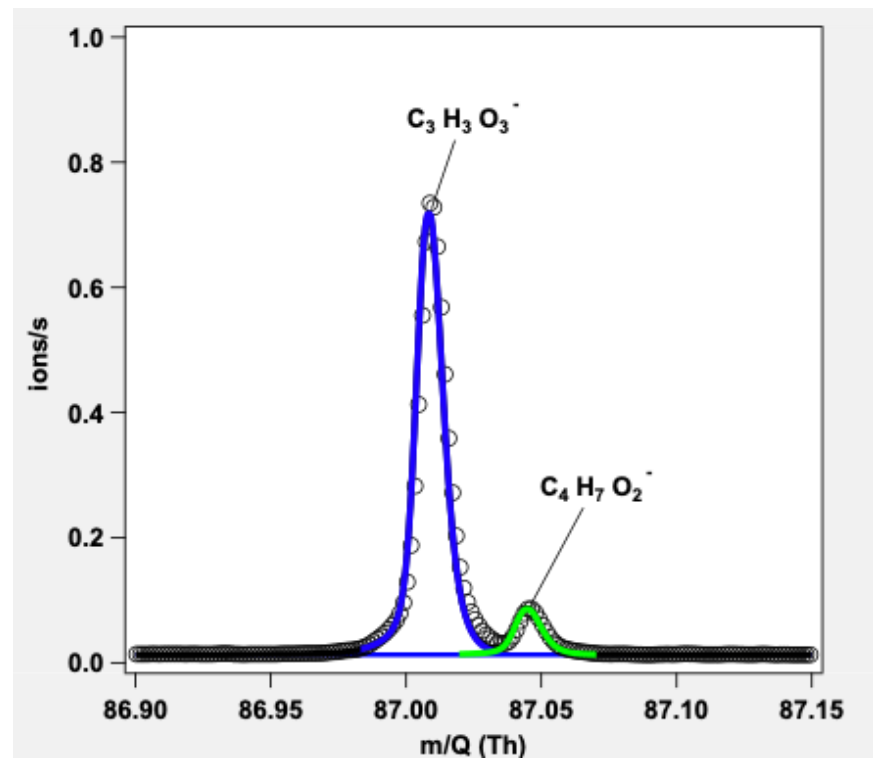

15 Figure S1: Signals measured by the HR-L-ToF-CIMS for the ions detected at $\mathrm{m} / \mathrm{z}, 87.008$ (assigned to pyruvic acid) and 87.045 (assigned to butanoic acid). 

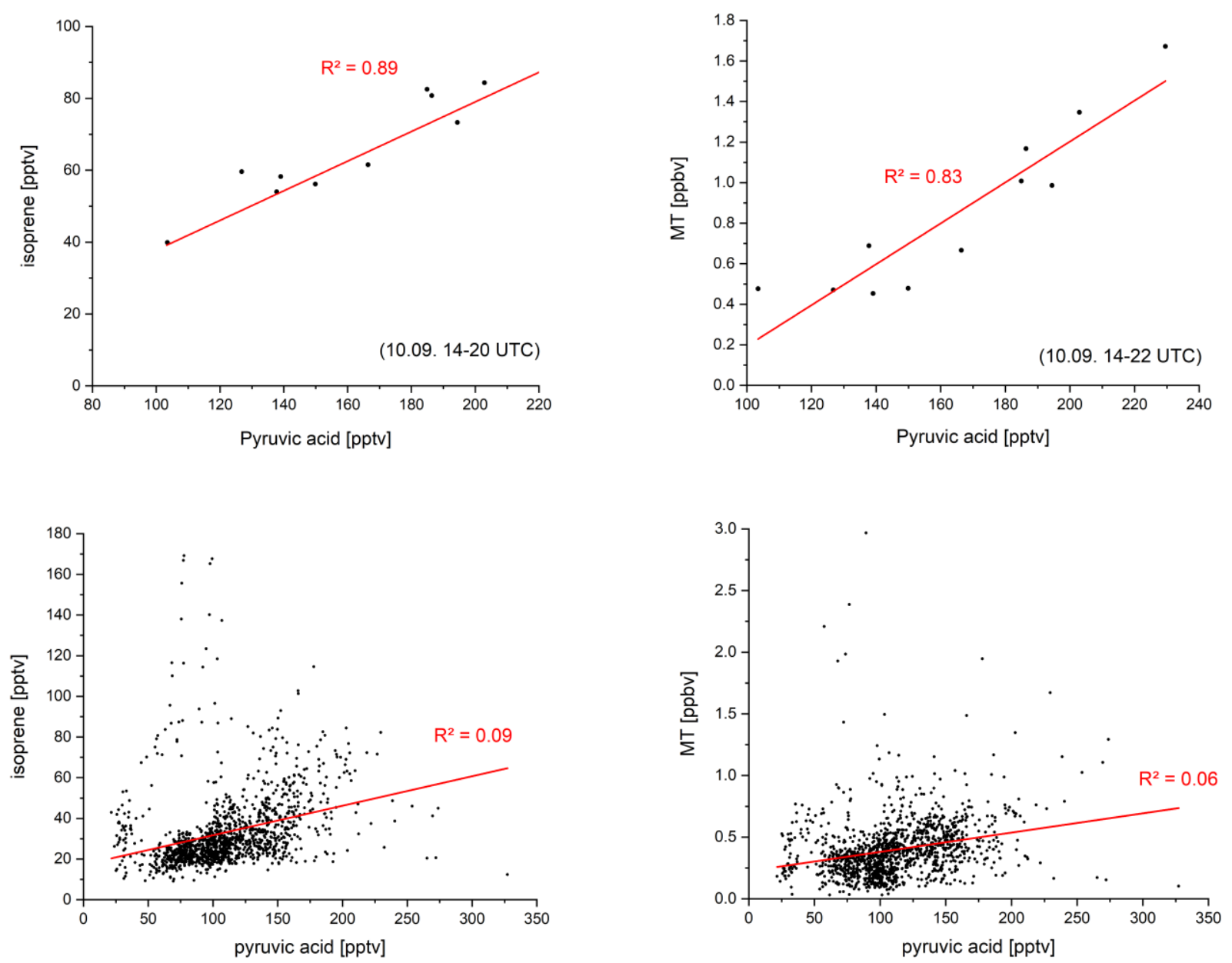

Figure S2: Upper panel: Correlation plots of pyruvic acid and isoprene / monoterpenes (MT) for 10 September 2016 (air mass influenced by sawmill). Lower panel: Correlation plots of pyruvic acid and isoprene / MT for the whole IBAIRN campaign. 


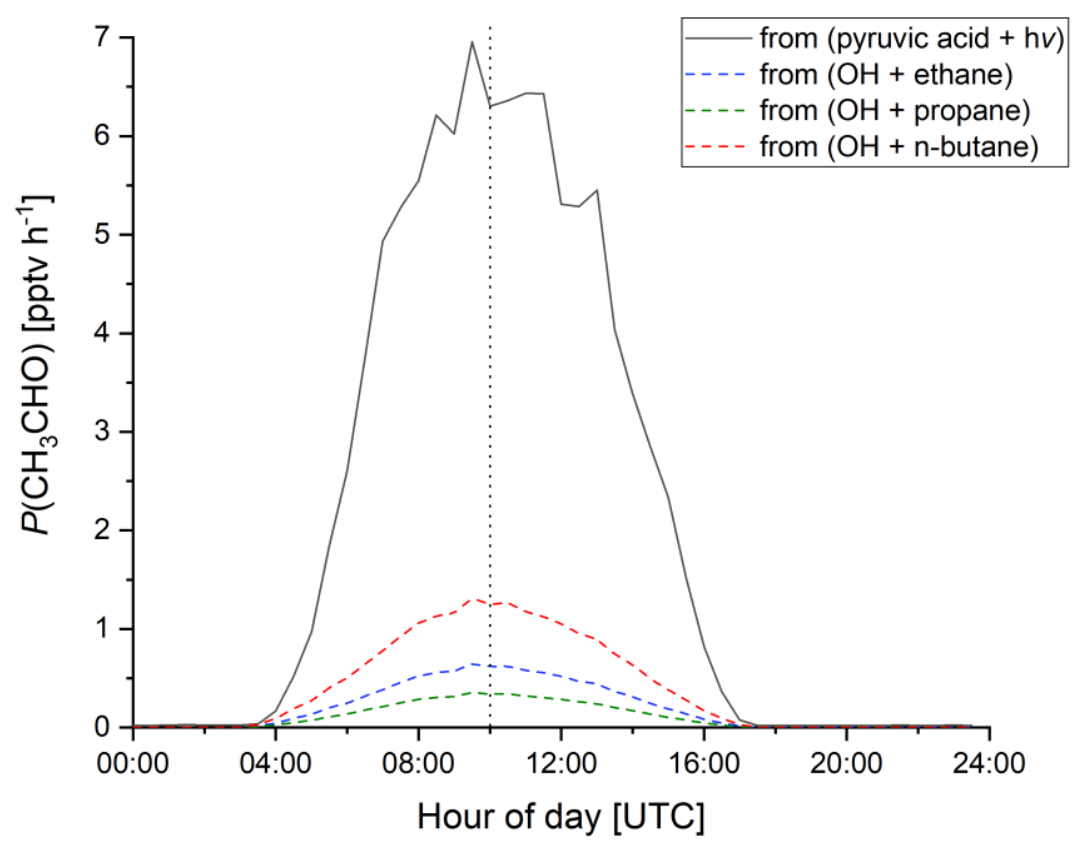

Figure S3: Acetaldehyde $\left(\mathrm{CH}_{3} \mathrm{CHO}\right)$ production rates over the diel cycle based on measurements (median diel profiles for IBAIRN) of pyruvic acid and $J_{\text {pyr }}$ (assuming a photolysis yield of $\varphi=0.2$ ), calculated $\mathrm{OH}$ and estimated mixing ratios of alkanes from literature data (see manuscript). The dashed vertical line indicates solar noon. 